
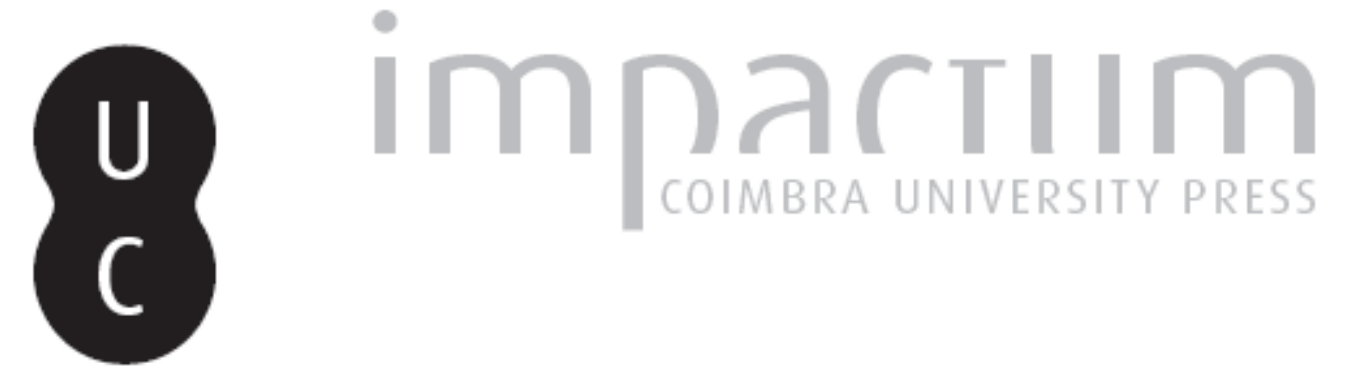

\title{
Análise e comparação do armamento na llíada e na Odisseia
}

Autor(es): Inocêncio, Joana

Publicado por: Centro de História da Universidade de Lisboa

URL persistente:

URI:http://hdl.handle.net/10316.2/23891

DOI:

DOI:http://dx.doi.org/10.14195/0871-9527_18_16

Accessed : $\quad$ 26-Apr-2023 14:23:14

A navegação consulta e descarregamento dos títulos inseridos nas Bibliotecas Digitais UC Digitalis, UC Pombalina e UC Impactum, pressupõem a aceitação plena e sem reservas dos Termos e Condições de Uso destas Bibliotecas Digitais, disponíveis em https://digitalis.uc.pt/pt-pt/termos.

Conforme exposto nos referidos Termos e Condições de Uso, o descarregamento de títulos de acesso restrito requer uma licença válida de autorização devendo o utilizador aceder ao(s) documento(s) a partir de um endereço de IP da instituição detentora da supramencionada licença.

Ao utilizador é apenas permitido o descarregamento para uso pessoal, pelo que o emprego do(s) título(s) descarregado(s) para outro fim, designadamente comercial, carece de autorização do respetivo autor ou editor da obra.

Na medida em que todas as obras da UC Digitalis se encontram protegidas pelo Código do Direito de Autor e Direitos Conexos e demais legislação aplicável, toda a cópia, parcial ou total, deste documento, nos casos em que é legalmente admitida, deverá conter ou fazer-se acompanhar por este aviso.

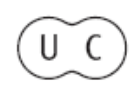



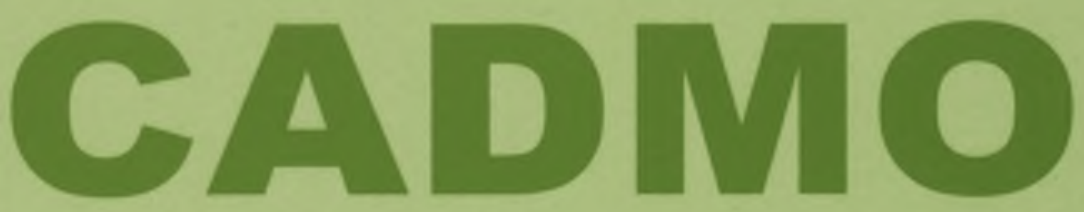

Revista de História Antiga

\author{
Centro de História \\ da Universidade de Lisboa
}

18

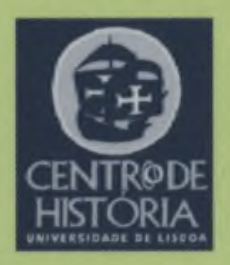

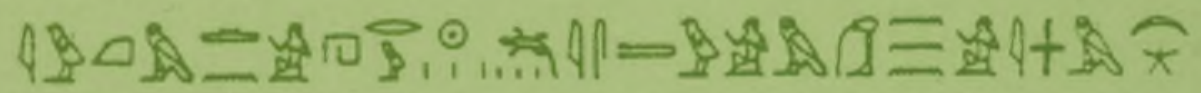

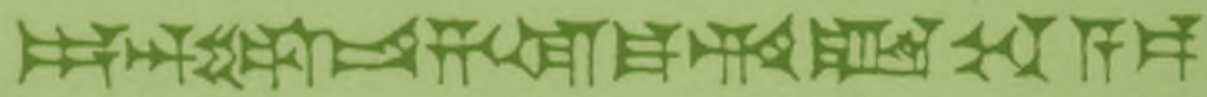

MHNIN AEI $\Delta$ E $\Theta E A ~ \Pi H \Lambda H I A \triangle E \Omega$ 


\title{
ANÁLISE E COMPARAÇÃO DO ARMAMENTO NA ILÍADA E NA ODISSEIA
}

\author{
JOANA INOCÊNCIO \\ Universidade de Lisboa \\ joaninharosa@ hotmail.com
}

Hoje considera-se quase unanimemente que Homero, ou pelos menos o primeiro autor a escrever a obra, terá vivido em cerca de 800 a. C. e as suas historias ter-se-ão passado por volta do século XII a. C. A datação da guerra de Tróia é uma das polémicas que a obra suscitou desde a Antiguidade Clássica - Eratóstenes datou-a como se tendo passado no ano 1184 a. C., Dúris de Samos data-a de 1334 a. C. e Éforo de Cime do ano 1135 a. C. - mas o século XII foi fortemente justificado como a mais correcta datação através das escavações de Schliemann na colina de Hissarlik ${ }^{(1)}$.

As escavações trouxeram à superfície toda uma cidade desconhecida. Esta teve a sua primeira ocupação na Idade do Bronze inicial com Tróia I (c. 3000 a. C.), e, com alguns hiatos ocupacionais, durou até ao período grego clássico e romano(2). Os registos hititas, as associações entre nomes de reis e de zonas que se cruzam e interligam com as evidências gregas e, principalmente as evidências arqueológicas, demonstram hoje que a Tróia de Schliemann é a de Homero ${ }^{(3)}$. Existem, no entanto, duas ocupações possíveis para a mesma, Tróia VIh e Tróia VIla, ambas destruídas por incêndios e ambas correspondendo ao fim da Idade do Bronze.

A guerra de Tróia e as descobertas de Schliemann em Tróia não são as únicas torres de apoio da Grécia micénica de Homero. As escavações em solo grego, como em Cnossos, Micenas, são fundamentais para analisar paralelos e para apoiar as evidências escritas. 
A Historia da Grécia também nos ajuda nesta certeza, uma vez que os nomes dos heróis eram nomes micénicos que são referenciados nas tabuinhas de linear B. Estas são uma crucial fonte de informação. Não só nomes como Hektor, Akhilleus ou Glaukos são micénicos ${ }^{(4)}$ como, segundo Page, os epítetos também são uma característica micénica ${ }^{(5)}$. Sabendo que Homero terá vivido em cerca de 800 a.C., na época que hoje historicamente denominamos como Dark Ages, e que esta não corresponde à realidade que ele retrata, podemos supor que as obras retratam ou a Idade do Ferro ou a Idade do Bronze, uma vez que a existência de metais não nos permite supor que sejam anteriores. No entanto, a Grécia, e não só, segundo Robert Drews ${ }^{(6)}$, sofreu uma tremenda alteração na passagem de uma época para a outra. Não só terá havido uma geral quebra no modo de governação com a queda dos palácios, como a invasão de um novo povo, os Dórios, possíveis causadores de tais mudanças, que introduziram novas realidades materiais como o ferro. No entanto, a questão das invasões suscita mais polémica. Quem eram os Dórios? A teoria mais comum parece ser a de que se tratava de um povo vindo do norte da Europa, mas outras defendem que a sua origem se situa nos países do leste europeu, e mais recentemente parece haver evidências de que os invasores poderiam ser apenas gregos do norte do país. Esta última teoria parece ser apoiada pela pouca alteração que a língua sofreu e pelo facto de não haver alterações nos padrões ocupacionais ${ }^{(7)}$. A teoria da vinda de populações dos Balcãs centrais apoia-se em algumas inovações, como a espada tipo Naue II e a cerâmica manual brunida que tem lá a sua origem ${ }^{8}$. Drews refuta o aparecimento destes elementos na Grécia como trazidos por populações migrantes apoiando antes a justificação de trocas comerciais.

Dado o cenário da obra guerreira se encontrar do outro lado do Egeu, pareceu-nos importante incluir nas análises tipologias de Tróia. No entanto, dada a polémica que o sítio levanta, ao ser retratado ora como ocupada por gregos $^{(9)}$ ora como uma cidade típica da Anatólia, decidimos não nos alargar nestas tipologias. Quanto às fases troianas de ocupação que nos interessam para a temática do trabalho - Tróia VIh e VIla - Alfred Götze ${ }^{(10)}$ estudou os objectos provenientes de ambas e declara não haver uma quebra cultural, mas sim uma continuação. Como tal, para o âmbito do estudo tipológico não interessa discutir qual a fase mais provável de ser a homérica.

A Idade do Bronze grega é famosa pelas suas construções palacianas minóicas. Os centros políticos eram regidos a partir do palácio 
onde o rei habitava. $O$ controlo religioso, político e social era feito pelo rei. Ao longo da Idade do Bronze diversos palácios foram sofrendo destruições, quer devido a acidentes naturais como terramotos quer devido a incidentes bélicos. Deste modo se deu sucessivamente a queda do grande palácio governativo e da maior influência no território grego, o palácio de Cnossos. Com a queda destes e a entrada do povo micénico na Grécia, o poder político mudou de localização. No fim da Idade do Bronze vimos emergir em Micenas as novas influências do mundo grego. O fausto inicial dos palácios é mantido até entrar em declínio e se extinguir devido à invasão dórica, pondo este novo povo um fim à Idade do Bronze. A nova Idade do Ferro traz com ela não só um diferente modo de governação como diversas inovações. O ferro é a maior e a partir dele muitas outras mudanças tipológicas aparecem.

A ligação entre a Grécia e o Egeu é de extrema importância para estudar a cultura material grega e troiana, uma vez que influências orientais são visíveis em diversos materiais gregos. De igual modo, o aparecimento de materiais tipicamente gregos em Tróia baseia-se no princípio das trocas comerciais. Estas parecem ter sido uma actividade comum nesta época essencialmente decorrente na zona oriental do Mediterrâneo.

Para uma melhor compreensão de certas realidades, explanamos apenas as cronologias básicas da Idade do Bronze final, mencionando previamente que as datações são semelhantes para Creta (EM, MM e $\mathrm{LM}$ ) e para o continente (EH, MH e LH). O Late Helladic é assim dividido em LH I (1650-1550 a.C.), LH IIA (1550-1470 a.C.), LH IIB (1470-1405 a.C.), LH III A (1405-1300 a.C.), LH IIIB (1300-1190 a.C.) e LH IIIC (1190-1050 a.C.)

No âmbito deste trabalho, foram realizadas duas tabelas com a recolha integral das citações referentes às realidades materiais de ambas as obras. Ė com base nelas que iremos analisar pormenorizadamente a cultura material e posteriormente comparar as obras.

\section{Elmos}

Homero utiliza, quatro palavras para mencionar os elmos - кópvৎ,

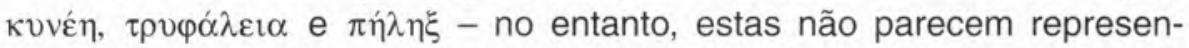
tar diferentes tipos de elmo, mas sim sinónimos, de modo a responder a exigências métricas especificas. ${ }^{(11)}$ 
Deverão ter existido diversos tipos de elmos. No entanto, dada a escassez de elementos reais, muita da tipologia e das evidências em relação a estes é-nos dada através das cerâmicas decoradas e dos frescos.

Os elmos podem apresentar algumas características básicas: protecções faciais (para o pescoço e/ou faces), cristas, penachos, tiras para segurar o elmo que prendem no pescoço e decoração. Em relação aos materiais, existem elmos totalmente em metal, por norma em bronze, mas que poderiam ter uma base em linho ou cabedal para comodidade, e elmos em couro ou pele não tratada, que poderiam ser reforçados com tiras, rosetas ou discos metálicos. As cristas e crinas de cavalo, suportadas por um nó ou suporte no topo do elmo, teriam não só uma função de impacte visual no adversário como também uma função estética. Do mesmo modo, a decoração dos elmos parece comum, podendo ser pintada ou feita através da aplicação de elementos de bronze, couro ou de chifres. Os chifres poderiam, tal como as cristas, ter uma função estratégica, de modo a provocar o medo no inimigo e a aumentar a ferocidade aparente do exército. Eram fixados em orifícios do elmo e suportados por estruturas metálicas devido ao seu peso. Outra característica evidente em alguns elmos parece ser o anel ou aro metálico inferior, que confere um suporte para toda a parte superior do elmo.

Podemos distinguir alguns tipos de elmos pelas suas características mais proeminentes. Um dos tipos de elmos mais antigos, mas também mais famoso pela sua excentricidade parece ser o Boar tusk ou Doloneia. Julga-se que este será uma realidade mais alargada dos inícios do Bronze e não uma especificidade grega, dada a existência de paralelos na Europa do Leste, como o exemplar de Mariupol, Ucrânia que data de 2000 a. C. O seu período de utilização parece chegar até ao Bronze médio. É composto por uma base de linho ou cabedal, à qual eram cozidas as presas de javali, que o representam. Podiam também possuir um anel de bronze na base, e geralmente tinha apenas três filas de presas. As presas podiam também ser cozidas nas protecções laterais. Não é possível determinar se as presas tinham uma função protectora ou apenas decorativa.

Outro tipo de elmo proveniente do Bronze Inicial e Médio é o elmo de bandas concêntricas. Não temos evidências reais deste elmo, como tal, não temos conhecimento do material com que era fabricado, sendo tão possível tratar-se de um exemplar de couro como de metal. Do mesmo modo, as bandas que o definem podem ser 
reforços metálicos ou de couro, ou podem apenas ser bandas decorativas pintadas.

Um dos principais elementos para o estudo desta época é o famoso Warrior vase. A sua especificidade decorativa, leva-o a mostrar-se um fiel representante da realidade guerreira. $O$ tipo de elmo representado nele é o tipo hedgehog. Dada a sua aparente fragilidade na representação, os especialistas definem-no como composto de materiais perecíveis como o couro ou mesmo peles não tratadas de animais. No entanto, possui algo que podemos descrever como decoração ou bossas metálicas de reforço. As saliências no topo são normalmente interpretadas como o pêlo de animal de que é feito ou como uma pequena crista.

O elmo do tipo Feather Headgear é caracterizado pela presença de um suporte metálico, o anel da base, e composto por tiras de cabedal ou de outro material perecível (as evidencias são unicamente representações) que, ao serem presas ao anel ficam soltas e esvoaçantes no topo, formando uma espécie de crista. O elmo tipo hollow-eyed é bastante semelhante aos de realidades mais tardias, possuindo uma protecção para o nariz, pescoço e lateral. É cónico, bastante simples, mas a sua aparência rígida e as evidências tardias levam a pensar que este tipo de elmo seria inteiramente fabricado em bronze.

Um elmo que aparece apenas no fim da Idade do Bronze e se estende para a Idade do Ferro é o Ko-ru-to, como aparece designado nas tabuinhas de linear B. É composto por quatro partes metálicas, denominadas o-pa-wo-ta, formando um elmo com o topo algo achatado, e com protecções faciais (pa-ra-wa-jo). Num exemplar encontrado num túmulo de Tirinto, é visível uma decoração triangular e circular em relevo e orifícios nas tiras centrais, provavelmente para a inserção de uma crista.

Muitos destes elmos tem paralelos tanto no Próximo Oriente, em regiões como o Egipto e a Síria, como na Europa do Norte e Central, mostrando alguma homogeneidade nesta área, justificando as semeIhanças entre os elmos troianos e os gregos.

Analisando as evidências das obras notamos que o elmo é o principal epíteto de Heitor. O herói troiano é referido constantemente como "Heitor do elmo faiscante" e é na comovente cena de despedida de Andrómaca que o penacho do mesmo assusta o pequeno Astíanax.

Mas muitos outros elmos são descritos, não só como elmo "faiscante" mas como "bem trabalhado", "com penacho de cavalo", "com farta crista de penachos de cavalo", "reluzente", "redondo", 
«terríveis», "medonho", "pesado", «ajustado às têmporas» e "belo e bem lavrado", mas que pouco ajudam para a classificação tipológica dos mesmos.

Mas algumas destas anotações permitem-nos chegar mais próximo da realidade. Muitos possuíam cristas, tornando-se assim relevante a menção a um elmo "sem corno e sem penacho". Quanto ao material, adjectivos como "faiscante», "fulgente", "coruscante» $e$ «luzente» levam-nos a pensar em metais, pois matérias animais não brilham naturalmente. Para confirmar isto temos menções exactas do material como "de bronze" e "pesado de bronze". No entanto, existem outras referências a diferentes materiais - "de cabedal» e "de couro taurino". Mas estas simples referências não nos explicitam qual das partes do elmo esta a ser retratada e, apesar da primeira tentação levar-nos a pensar no exterior há uma outra referência, "e por dentro havia um forro de pano" que nos empurra para olhar para os forros interiores dos elmos. Estes forneceriam um maior conforto e uma melhor adaptação à cabeça, permitindo que o elmo ficasse "ajustado às têmporas".

Quanto aos apetrechos temos evidências dos já mencionados penachos, mas também de chifres - «de dois chifres e quatro bossas com penachos de cavalo que se agitavam, terríveis, de cima" e "de quatro chifres" - de decoração ou reforços - "de brônzeos bocetes" e "com bocetes de bronze" - e ainda uma referência a um elmo "com uma saliência". Quanto às menções de bossas ou bocetes, torna-se praticamente impossivel a distinção da sua função pois, apesar de não haver nenhuma referência a qualquer pintura ou cor dos elmos, não podemos excluir a possibilidade de estes terem decorações incisas ou em relevo. Quanto há referência da saliência, esta pode ter uma função decorativa ou de reforço, mas também pode tratar-se de uma estrutura final para suportar a crista. A Odisseia menciona um elmo "com faces de bronze", o que pode significar a existência de protecções laterais - de face ou de nariz - nos elmos. Parece ser a única referencia a tais protecções.

Em relação a tipologias específicas, através da citação «feito de couro, retesado por dentro com muitas tiras de cabedal, por fora, cerradas, estavam dispostas as brancas presas de um javali de reluzentes colmilhos, deste lado e daquele, com excelente perícia” podemos claramente classificar este elmo como um elmo Boar tusk.

O elmo "de couro taurino, sem corno e sem penacho, elmo a que se chama "acachapado" " é muito provavelmente um elmo tipo 
hedgehog. A menção a um "triplo elmo de penacho" pode tratar-se dos exemplares mencionados nas tábuas de linear B, uma vez que, apesar de constituído por quatro partes, a sua aparência era triangular, não sendo de estranhar, dado o tempo que separa a realidade dos relatos da mesma, que haja uma menção a um elmo triplo e não quadruplo, como seria correcto.

As armas de Aquiles parecem tratar-se sempre de uma excepção à regra. A descrição do elmo - "brilhou como uma estrela o elmo com crinas de cavalo, e à sua volta se agitaram os penachos dourados que Hefesto colocara cerrados à volta do elmo" - mostra penachos dourados o que pode ser evidência de pintura ou de penachos feitos de ouro. A referência à colocação dos penachos em volta do elmo expõe uma crista que percorria o elmo ou penachos soltos colocados arbitrariamente à volta do mesmo. Parecem não existir paralelos arqueológicos para este tipo de colocação, no entanto os penachos e crinas são materiais perecíveis que não aparecem no registo arqueológico.

Por fim o elmo de Atena - "de dois chifres e quatro bossas, dourado, equipado com os peões de cem cidades" - é também invulgar. Os chifres e as bossas são comuns, mas o facto de ser dourado implica que o elmo seja pintado ou feito de ouro. Esta evidência, uma vez que se trata da descrição de uma deusa tem de ser olhada com cuidado. As evidências referentes aos deuses são por vezes subjectivas, podendo ter sido feitas, menos com a intenção de descrever o real e mais com o intuito de favorecer os deuses para os agradar, mostrando-os sempre diferentes e melhores do que a realidade. A referência aos peões de cem cidades parece-nos confusa, só podendo observá-la como um motivo decorativo.

\section{Escudo}

O escudo é, na llíada, a peça pertencente à cultura material que mais se evidência, dada a famosa descrição do escudo de Aquiles. Duas palavras são utilizadas por Homero para escudo - бóko̧ e

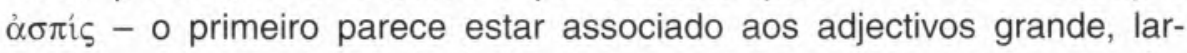
go, feito de sete peles de boi e como uma torre, o segundo associase às bossas e à forma redonda. Apesar de não usarem os adjectivos do outro não significa que não possam ter as mesmas características, como o caso do escudo de Aquiles que se julga redondo mas é sempre 


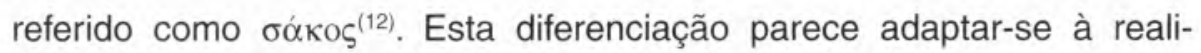
dade, diferenciando body shields de escudos tardios.

De acordo com as fontes arqueológicas, podemos falar de três tipo de escudos de corpo inteiro ou body-shields - o tower shield, o figure-of-eight shield e o proto-Dipylon. Estes tipos de escudos são mais característicos do início da Idade do Bronze, apesar de o seu uso ser atestado até mais tarde.

O primeiro tipo consiste num grande escudo rectangular, cuja função era cobrir e proteger todo o corpo. O escudo em oito (figure-of-eight shield) tinha a forma cujo nome indica, era feito de pele de boi esticada numa moldura de madeira, de modo a criar a sua forma específica. De lado mostra uma curvatura convexa tanto vertical como horizontal ${ }^{(13)}$. E o proto-Dipylon era um escudo redondo ou oval com duas entradas laterais, algo similar ao figure-of-eight mas mais suavizado.

Os escudos, de uma forma geral, eram constituídos essencialmente por camadas sobrepostas de pele de animal, tratada ou não, que eram depois coladas ou encaixadas através de juntas ou arames a estruturas de vime ou outro tipo de madeira flexível. É provável que alguns escudos tivessem um reforço central de madeira ou metal para garantir uma maior eficácia e uma camada de couro a rematar todas as extremidades do escudo. Poderiam também ter pequenos reforços exteriores em metal ou madeira. As estruturas que interpretamos como reforços também podem ser formas de decoração ou rebites para prender as diversas camadas de couro. Muitos dos escudos podiam ter um rim de reforço na zona central, de madeira ou bronze, colocado verticalmente, muitas vezes pintado.

A pequena pega que alguns escudos possuem no seu interior seria provavelmente para manobrar o escudo em batalha e não para o transportar. Lorimer defende que, independentemente dos escudos serem completamente redondos ou abaulados na base, escudos com uma única pega permanecem em uso ate à adopção do equipamento hoplita em 700 a. C. ${ }^{(14)}$ As tiras corriam por cima do ombro esquerdo e passavam por debaixo do braço direito, de modo a carregar os escudos quando não estavam a ser usados, permitindo que estes ficassem fixos nas costas não impedindo a movimentação(15).

Os escudos de corpo inteiro eram mais comuns no período inicial e médio da idade do bronze, não caindo em desuso no fim da mesma, no entanto, o aparecimento das couraças e os avanços nas técnicas de trabalho do bronze tornaram um escudo tão grande pouco 
prático e viável. Deste modo surge um outro tipo de escudo, mais adaptado às novas necessidades.

Por volta do LH IIIB aparece um novo tipo de escudo, o escudo redondo - aspis. Este escudo, descoberto pela primeira vez por Wolfgang Helbig, era razoavelmente mais pequeno que os anteriormente descritos. É caracterizado pela sua forma, pelo seu exterior cónico que vai da bossa ao rim e por possuir um centro e simetria ${ }^{(16)}$.

Apesar das tipologias se remeterem para a realidade grega, dada as trocas comerciais, as realidades troianas não deveriam ser muito diferentes, como pode ser atestado pelo objecto que Schliemann encontrou em Tróia, e que pode ser interpretado como parte de um rim e uma bossa central de um escudo redondo. Independentemente da interpretação da descoberta, ao analisar realidades hititas e egípcias podemos observar semelhanças no que toca ao armamento.

O escudo de Aquiles é talvez o mais famoso passo da llíada, mas o escudo é mais vulgarmente descrito como "possante", "resistente", "bem equilibrado nos lados", «fulgente", "trabalhado", "alvejados", "protector», "brilhantes", "amplo», «luzente», "vasto», "enorme", "bem forjado", "pequeno", "melhor", "que chegava ao chão, protecção contra dardos", "rebordo do escudo", "grande", "largo, mas já velho, manchado pela humidade", "robusto", "belo", "variegado".

Quanto ao material de que é feito temos o escudo descrito como "de touro", "de pele de boi", "de couro curtido", "bovino", "de sete camadas de pele de boi", "de bronze", "bem equilibrado, espesso com peles de boi e trabalhado com muito bronze", "de pele de boi, fortes e ásperos, em cuja feitura havia bronze abundante», "bem equilibrado, espesso com peles de boi e trabalhado com muito bronze", "de pele de boi, fortes e ásperos, em cuja feitura havia bronze abundante" e alguns epítetos já referidos que remetem para o metal como "brilhantes". Deste modo o material dos escudos coadune-se com a realidade material que conhecemos. Duas excepções são as menções aos escudos de Nestor e Aquiles - "todo feito de ouro, tanto as barras como o escudo em si"», "pois o ouro a reteve (...). Porém penetrou duas camadas, só que havia ainda mais três, pois cinco eram as camadas que forjara o deus de pé manco; duas de bronze, mais duas de interiores de estanho, e uma de ouro" e "reteve-a o ouro" - sendo pouco provável o uso do ouro, mas não impossível, como podemos ver pelo exemplar de Micenas. Estes escudos em ouro são sempre escudos de heróis, o que provavelmente significa que na realidade 
estes escudos só seriam fabricados para ocasiões especiais como contextos votivos.

Quanto à execução temos evidências de como os escudos eram constituídos por camadas - "de quatro camadas", "de sete camadas de pele de boi", "reluzente com sete peles de touros (...) e por cima a oitava camada de bronze", "terrível escudo de Ares com o couro de sete bois, na parte de fora de bronze, a oitava camada que tinha por cima. Através de seis camadas penetrou o bronze intransigente, mas no sétimo couro foi retido", "escudo de Eneias, equilibrado de todos os lados, sob o rebordo exterior, onde o bronze corria finíssimo e finíssima era a camada de pele de boi" - cujos materiais poderiam variar, assim como o número de camadas. $E$ evidências das molduras interiores ou barras de reforço - «escudo esse trabalhado com pele de boi e bronze brilhante que costumava levar, provido ainda de duas barras" e "todo feito de ouro, tanto as barras como o escudo em si».

No que toca à decoração ou ao reforço temos escudos "cravejado", "cravado de adornos", "cravejado de bossas", "adornado de bossas", "bossa do escudo", "bossudo" e "ornado de bossas". A constante menção a bossas mostra a presença do metal nos escudos, independente da sua função decorativa ou funcional.

As referências "redondos" e "como uma torre, brônzeo com o couro de sete bois" mostram a forma do escudo, mostrando as diferentes tipologias mencionadas. A última refere-se ao escudo de Ájax. Este é constantemente mencionado como tratando-se de um tower shield, e Wace e Stubbings (1970) chegam mesmo a defender que Ájax é, todo ele, uma representação de um guerreiro do início da Idade do Bronze, pois, além do seu grande escudo também não possui couraça. Esta duplicidade entre a couraça e o escudo remete para as razões pelas quais os grandes escudos caem em desuso.

O escudo de Agámemnon é descrito como «ricamente trabaIhado e valoroso, que protegia um homem de cada lado: escudo belo que tinha dez círculos de bronze, e por cima vinte bossas de estanho branco e luminoso, tendo no meio uma bossa de escuro azul. Coroava-o como grinalda a Górgona de horrível aspecto, (...) junto dela estavam o Terror e o Pânico. Do escudo pendia um boldrié de prata; e por cima serpenteava uma serpente de azul». Este escudo à primeira vista, pelo uso de círculos de bronze, parece tratar-se de um escudo redondo, no entanto, um escudo redondo não "protegia um homem de cada lado". Deste modo, ou temos evidências de um figure-of-eight shield, de um proto-Dipylon ou de um escudo redondo maior. 
A sua decoração é excêntrica, pois é a única a ter imagens ${ }^{(17)}$. Apesar de não haver representações deste género de escudo, ele parece ter semelhanças com um tipo de escudo arcaico inicial votivo em bronze encontrado na gruta Idaean em Creta. Estes são compostos por figuras em relevo colocadas de modo concêntrico e com uma bossa central com a forma de um animal grotesco. A existência de Éris e Fobo parece ser conhecida na época de Homero, mas não sabemos quando começou, logo pode ser uma inclusão do tempo de Homero e não uma realidade micénica ${ }^{(18)}$.

O escudo de Sarpedón é o único que faz referência ao método de junção dos materiais uns aos outros e à estrutura de madeira - «bem equilibrado, belo escudo de bronze martelado (...) cosendo por dentro as espessas peles de boi com grampos dourados no perímetro do rebordo" - a partir de grampos ou outro tipo de estrutura semelhante.

O escudo de Aquiles era "grande e robusto, todo lavrado, e pôs- Ihe à volta um rebordo brilhante, triplo e refulgente, e dai fez um talabarte de prata. Cinco eram as camadas do próprio escudo, e nele cinzelou muitas imagens com perícia excepcional» e dessas cinco camadas eram "duas de bronze, mais duas de interiores de estanho, e uma de ouro". É claramente um escudo divino, cujos paralelos reais dificilmente existiram, especialmente no que toca à decoração, demasiado perfeita para ser executável. Apesar do escudo não mencionar a sua forma, mas ser referido como "grande", seria de esperar que o autor, ao falar do escudo do grande herói Aquiles, se referisse ao tipo de escudo mais eficiente do seu tempo. Deste modo, tratar-se-ia do escudo mais recente, um escudo redondo. No entanto, não podemos categoricamente afirmar isto, pois a obra não apoia completamente esta dedução.

A sua decoração era cinzelada e em relevo, contendo imagens astrológicas, da vida quotidiana e marinhas. As constantes referências a metais nas descrições das imagens levam a julgar que diferentes metais foram usados, entre os quais o ouro, bronze, estanho e prata. De estranhar é o talabarte de prata pois este é, ainda hoje, uma peça de material perecível como tecido ou couro, sendo pouco prático o seu fabrico em metal. Pode assim tratar-se de sobrevalorização do escudo, não sendo na realidade uma peça comum no mundo micénico.

Independente destes escudos mais específicos, a llíada parece representar variados tipos de escudos, que poderiam estar todos em uso em simultâneo. Mas, não pode, em qualquer campo analisado, ser rejeitada a hipótese de Homero ter colocado evidências do seu 
tempo, ou de tempos que lhe são mais próximos, mas não necessariamente micénicos, uma vez que não possui um conhecimento directo da época que retrata.

\section{Armadura - Couraça}

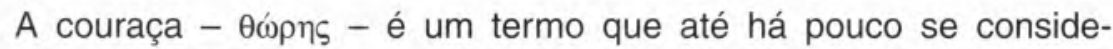
rava uma menção intrusiva nos textos homéricos, hoje sabemos que está atestada pelo menos a partir do século XII a. C., dada a sua presença nas tabuinhas de $\operatorname{Pilos}^{(19)}$. Hoje, não só temos as tábuas como estudos dos elementos iconográficos e algumas descobertas arqueológicas a atestar a existência de couraças micénicas. Estas poderiam ser tiras ou placas de metal cozidas a uma túnica de cabedal ou de outro material ${ }^{(20)}$ ou consistir em duas placas centrais do torso às quais se vão ligar outras placas, mas tendo no interior uma estrutura em linho para as unir e tornar a estrutura mais confortável.

As tábuas de linear $\mathrm{B}$ de Cnossos e de Pilos, datadas do século XIV e XIII a. C. demonstram couraças (to-ra-ke) com o comprimento de túnicas ${ }^{(21)}$. Apresentam linhas curvas nos ombros o que provavelmente reflecte as peças de protecção dos mesmos (apelidadas de e-po-mi-jo nas tábuas). Diferentes linhas aparecem ao longo do torso aludindo às diversas peças soltas de metal utilizadas, aos cinturões ou a decorações, não nos permitindo tirar conclusões mais concretas. No entanto, o seu formato é variável podendo aparecer em formato de sino e mais compridas ou mais curtas e rectas. Outro tipo de peça é descrita, o o-pa-wo-ta, que parece indicar um tipo de acessório, provavelmente reforços metálicos da couraça ${ }^{(22)}$. Existem evidências físicas destas representações que as confirmam. Uma delas é o achado de Dendra. Este achado data de cerca de 1450 ou 1400 a. C. Pelas imagens podemos ver que se trata de uma couraça composta por diversas partes metálicas, duas para o torso, protecções para os ombros, protecção para o pescoço, e cerca de seis tiras, três para a frente e três para trás para protecção do torso para baixo. Todas as partes metálicas continham pequenos orifícios, e foram achados resíduos de linho e de pêlo de cabra, levando a pensar que existiria uma couraça interior em linho onde seriam cozidas com couro de cabra as peças metálicas.

As placas em ouro encontradas na Shaft Grave V em Micenas, podem fazer parte de uma couraça construída a partir de materiais 
perecíveis. O facto de serem de ouro leva a pensar que se tratasse de um exemplar de imitação usado como símbolo de prestígio. No entanto, e observando as alusões na llíada, podemos pensar que os guerreiros das elites poderiam possuir elementos em ouro, especialmente nas couraças, pois estas são um elementos de protecção pessoal que não se perde facilmente como uma espada ou lança.

Outro possível tipo de couraça pode ser vista no Warrior vase. Aí um guerreiro parece vestir uma couraça curta, que não ultrapassa o nível da cintura, sem cinto. Por baixo da linha da cintura vimos a túnica ou kilt, que poderia ser de tecido ou, mais provavelmente, de couro $^{(23)}$.

No entanto este tipo de couraça cujos elementos metálicos são minoritários em relação aos materiais perecíveis é uma couraça dos inícios do bronze. Apesar de não ter caído em desuso, no fim do Bronze os Aqueus parecem ter adoptado o tipo de couraça do próximo oriente, a couraça de escamas. Apesar de nenhuma armadura completa ter sido encontrada, várias escamas foram encontradas, atestando o seu uso por todo o território grego. Segundo Drews ${ }^{(24)}$ em Nuzi foram encontradas escamas que remetem para um tipo de couraça, denominada sariam, por ele descrita como sendo uma túnica de cabedal comprida, com mangas e cerca de quinhentas escamas de cobre nela cozidas.

As referências a armaduras e couraças nas obras homéricas mostram claramente que existiriam elementos metálicos nas mesmas. Estes não excluem a existência de túnicas de couro ou tecido que são inclusive mencionados. A alusão a uma armadura "embutida em bronze" é evidência de armaduras que não são, na sua totalidade, fabricadas em bronze.

Parece haver uma distinção entre os dois termos - armadura e couraça - nas duas obras, uma vez que a couraça é apenas referenciada na lliada. No entanto as suas características básicas são análogas. Em contrapartida algumas destas couraças são bastante descritas - "por cima estavam dez tiras de escuro azul, doze de ouro e vinte de estanho, serpentes azuis entrançavam-se até ao pescoço, três de cada lado semelhantes ao arco-íris", "espessa couraça que envergava, adornada de mossas redondas", "variegada, ornada de estrelas" e "é de bronze e tem por cima adornos circulares de estanho brilhante" - mostrando claramente o uso do metal para decoração. Esta decoração pode ser em forma circular, em tiras ou estrelas, sendo que não aparecem paralelos materiais para a última. 
A primeira descrição mostra diversas tiras metálicas. Estas podem ser vistas como as tiras que constituem a couraça, apesar de o seu número parecer exagerado para tal, como escamas, referindo-se assim a uma couraça de escamas, ou como elementos decorativos. O "escuro azul» não parece referir-se a metal, mas talvez a couro pintado, mostrando assim claramente uma intenção decorativa. Esta é reforçada pelas "serpentes azuis", claramente decorativas, cujo material de fabrico nos é desconhecido.

Quanto ao seu comprimento, característica que nos ajudaria a diferenciá-las, não temos qualquer menção. Mas ao estudar as descrições referentes aos locais onde as armas penetram nas armaduras, podemos pensar que muitas se prolongariam para baixo do cinto(25). Independentemente de algumas características visíveis na obra, não é possível atribuir tipologias mais especificas às couraças.

\section{Cnémides}

As cnémides também são algo controversas pois, tal como as couraças, foram inicialmente julgadas como inclusões mais recentes, atestando-se o seu aparecimento apenas com a eclosão do equipamento hoplita. Descobertas arqueológicas mostraram que a sua existência data já desde a Idade do Bronze. E, segundo Drews ${ }^{(26)}$, as cnémides metálicas são uma invenção grega do século XII a. C., que desaparece tão misteriosa e rapidamente como apareceu em c. 1150 a. C. para voltar a reaparecer no século VII a. C. No entanto, o achado mais antigo de cnémides parece datar de 1400 a. C., deitando por terra parte da teoria de Drews. Para paralelos em materiais perecíveis não temos datações pois estes não sobrevivem arqueologicamente.

Este elemento de protecção, tal como a maior parte da cultura material ligada à guerra do Bronze Final grego pode ser dividida em exemplares de couro e outros materiais perecíveis e em exemplares metalicos. As poucas representações e achados levam a pensar que o seu uso não seria muito comum, no entanto, este é o principal epíteto dos Aqueus - "Aqueus de belas cnémides". Podemos supor que o epíteto se deve a um caso particular, sendo assim comprovado o pouco uso de cnémides com excepções como os Aqueus. Não justificando as poucas representações, a falta de achados arqueológicos pode indicar um uso maior de cnémides em materiais perecíveis que não sobreviveram até aos dias de hoje. 
Os exemplares metálicos, os únicos sobre os quais temos informação, são constituídos por uma única peça de metal que cobre toda a zona frontal da tíbia, podendo ou não cobrir o joelho na continuação da peça ou com uma peça adjacente. A zona traseira pode conter orifícios ao longo do comprimento para passar um fio de modo a ajustar e prender a cnémide. Outras poderiam fixar-se ajustando-se naturalmente ao formato da perna, como parece ser o caso do exemplar de Dendra, já mencionado.

Poderiam ser decoradas, como é visível nos exemplares de Kallithea e de Atenas, sendo os elementos decorativos mais comuns figuras geométricas como linhas ou círculos. Pode também existir decoração em relevo ou repoussé(27). Os frescos de Micenas, Tirinto e Pilos parecem manter uma uniformidade quanto à representação de cnémides. Estas aparecem pintadas de branco, com linhas horizontais, cujo número varia entre três e sete. A parte frontal superior tem a forma de um arco elevado, de modo a proteger o joelho.

A descoberta, em túmulos de Torre Galli, no Sul de Itália, de esqueletos usando apenas cnémides e protecções de braços no lado direito do corpo parece sustentar a teoria do uso de apenas uma cnémide. Esta teoria prende-se a questões simbólicas e de estatuto social, ou a questões defensivas, em que o uso de um escudo de corpo inteiro protegeria todo o lado esquerdo do guerreiro, deixando, no entanto, o lado direito descoberto. Como tal, a cnémide usada desse lado serviria de protecção adicional. Pensa-se que este uso unilateral terá sido comum apenas até ao século XII a. C., podendo a sua posterior passagem para as duas pernas se dever ao uso do escudo redondo, que oferece menor protecção corporal, ou devido ao significado simbólico das mesmas ter sido alterado ${ }^{(28)}$.

Como foi mencionado, o epíteto mais utilizado para esta estrutura é "belas", mas as cnémides são também referidas como "brônzeas", "de estanho moldável», "de estanho de forja recente" e "adornadas de prata na parte ajustada ao tornozelo" ao longo da llíada. No que toca à Odisseia elas são essencialmente referidas como epíteto, quer dos Aqueus quer dos companheiros de Ulisses, sendo deste modo sempre "belas joelheiras", com excepção de uma única menção a cnémides "de cabedal cosido".

São claras as evidências de ambas as matérias-primas mais comuns - cabedal e metal - assim como referências à decoração, mas não é dada nenhuma informação acerca do tamanho e método de prender as mesmas. 


\section{Arco}

Existem dois tipos de arco na Idade do Bronze grega - o arco simples e o compósito. $O$ arco simples grego podia ser reforçado ao serem-lhes colados tendões animais de modo a não quebrar e a ganhar elasticidade e podia assumir diversas formas desde o curvo simples aos duplos convexos ou côncavos. O arco compósito é composto normalmente por madeira, tendões e chifres animais.

As tábuas de linear B de Cnossos mostram que os gregos sabiam usar e fazer o arco compósito ${ }^{(29)}$. Em contrapartida, Wace e Stubbings ${ }^{(30)}$ defendem que não há evidências materiais arqueológicas nem representações deste arco. Apesar de recentes descobertas iconográficas poderem mostrar arcos compósitos, a representação nunca é explicita o suficiente para não haver dúvidas.

Apesar da simplicidade no tratamento do arco, este parece ter alguma influência nas obras de Homero. Se por vezes na llíada é visto como uma arma inferior, com Ulisses e Apolo o arco ganha grande importância. O facto de a única arma conhecida de Apolo ser um arco de prata, mostra que não poderia tratar-se de uma arma de pequena importância.

O arco de Ulisses adquire uma importância fundamental essencialmente na Odisseia. É devido a ele que Ulisses é reconhecido e o carácter fenomenal do arco é várias vezes mencionado. Trata-se claramente de um arco compósito, muito provavelmente feito maioritariamente de corno, o que o tornava tão difícil de manusear. A importância dada ao arco nesta obra pode parecer demasiada numa época em que o desenvolvimento do metal dá origem a armas mais eficazes. Assim deverá tratar-se mais de uma reminiscência da importância que o arco tem desde a pré-história e que os heróis adoptam como simbólico.

O arco é pouco descrito nas obras, sendo que referências como "possante», "polido», «irrepreensível», «inútil», "de prata», «recurvo», "glorioso", "grande", "desnudo", "famoso" e "poderoso" pouco nos dizem, especialmente se tivermos em conta que o "arco de prata" é um epíteto de Apolo, não podendo assim ser analisado como parte da cultura material micénica. Ainda assim quatro descrições do arco fornecem-nos preciosas informações - «bem polido do chifre de um bode selvagem...os chifres nasciam-Ihe da cabeça com dezasseis pés de comprimento, e o artífice de chifres ajustara-os bem, alisando tudo com cuidado e adornando a ponta com ouro", "que retesou, depois 
de o ter apoiado bem no chão", "que flectia para trás» e "que se dobrava para trás" - como claras menções a arcos compósitos, pois os arcos simples não se dobram para trás. Quanto à única menção do material, este arco parece ser formado pelos chifres inteiros de um bode, sem qualquer referência a madeira, e com o pormenor da decoração a ouro. Na realidade, arcos construídos deste modo seriam muito difíceis de manejar. Ainda que o arco de Ulisses possa ser um arco compósito todos os outros podem facilmente tratar-se de arcos simples de variadíssimas formas. As conclusões são assim diminutas.

\section{Aljavas}

As aljavas eram certamente fabricadas em materiais pereciveis o que torna quase impossivel o seu aparecimento em contextos arqueológicos. O seu estudo é feito principalmente a partir de imagens, que também não abundam. No entanto a sua existência pode ser atestada por provas indirectas, como a presença de uma concentração de pontas de seta num local específico, como é o caso do túmulo do caçador em Zapher Papoura, perto de Cnossos, que leva a supor que as setas estariam arrumadas no interior de uma aljava. Alguns elementos de marfim e metal encontrados também podem pertencer a aljavas.

As aljavas descritas nas obras não oferecem mais indícios que ajudem na sua pormenorização, com excepção de que poderiam possuir uma qualquer espécie de tampa, provavelmente também de couro e que esta poderia ser dupla - "duplamente coberta" e "tampo da aljava".

\section{Setas}

As setas, sempre associadas aos arcos, podiam ter a ponta nos materiais comummente utilizados desde a pré-história, pedra lascada e osso, mas agora, com a emergência das técnicas de trabalho de metais, também podiam ter uma ponta em bronze.

Em ambas as obras são descritas como "malignas", "amarga", "aguda», "veloz", «imparáveis», "dadoras de morte veloz», "penetrante», "apetrechada de asas», "brandas», "poderosas", "dadoras de gemidos" e "portadores de gemidos". No entanto este tipo de informação pouco serve pois apenas fornece características físicas dos 
efeitos que as setas provocam. Informações fornecidas pela llíada referem "entalhes de seta", "cana da seta" e "seta dourada". As duas primeiras menções referem-se à constituição da seta, que pode referir-se à colocação de penas ou pêlos no cabo da seta, enquanto a última mostra que as setas poderiam ser pintadas ou manufacturadas em ouro, tanto a ponta como o corpo. Infelizmente, como já comentado, não temos provas físicas de nenhuma das hipóteses. Quanto à ponta das setas, estas são geralmente referidas como "brônzeas" ou "de bronze", não havendo qualquer tipo de referência a pontas de pedra, apesar de haver uma referência a uma ponta "de ferro". A menção ao ferro é sempre vista como um elemento estranho às obras, inclusive porque é pouco referido.

Nas setas incluímos também as alusões a flechas. Estas são descritas como "ao ser arrancada se quebram as barbas pontiagudas", "célere", "amarga", "aguda", "pontiaguda", "apetrechada de asas", "poderosa", "de farpa tripla", "compridas barbas", "veloz", "douradas" e "rápidas". Como se pode verificar, parece clara a menção às farpas e barbas, que devem ser inclusões de penas ou pêlos como já comentado. As setas douradas são pertencentes a Ártemis, mostrando que esta realidade pode ser pouco real.

\section{Lanças}

Ao longo da llíada temos duas realidades no que toca às lanças - o uso de uma única ou o uso de duas simultaneamente. Homero denomina-as diferentemente, quando o herói usa só uma utiliza o termo

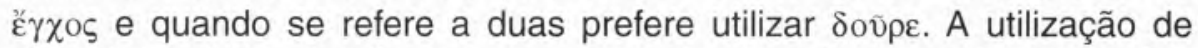
uma única lança implica uma arma mais pesada para ataques próximos, enquanto que as lanças usadas em conjunto seriam mais leves, para atirar a grandes distâncias. No entanto ao longo da obra observamos que ambas as palavras são usadas para lanças cujo objectivo é o lançamento à distância. Sabemos que as lanças pesadas para atacar eram comuns no tempo micénico, e sabemos que as lanças mais leves para arremesso existem pelo menos desde o período geométrico, mas não sabendo se realmente já existiriam no fim da idade do bronze ${ }^{(31)}$.

Algumas lanças na obra são descritas como "de bronze», "forte», "potente», «reluzente», "possante», "pontiaguda», "brilhante», «imponente", "selvagem", "bem ajustada às suas mãos". Em relação à 
dimensão temos lanças "pesada», "enorme», "de onze cúbitos», "monstruosa", "comprida", "longa" e "de longa sombra" não havendo qualquer menção a lanças mais pequenas.

Quanto à ponta esta é sempre de bronze, mas quanto à forma podem ser "de dois gumes» ou "de dupla ponta». Esta alusão parece ligada mais à forma da ponta do que à real existência de duas pontas. Quanto ao cabo este era de madeira pois são mencionadas lanças "de freixo". A junção é claramente descrita como um tipo de encaixe - "quebrou-se no encaixe" - o que é uma característica comum nas lanças. Um dos poucos pormenores mencionados é o anel de ouro - "brônzea ponta em torno da qual passava um anel de ouro". Este pode tratar-se de um pormenor decorativo ou fazer parte da estrutura que ligava a ponta ao cabo da lança.

Por fim é curioso mencionar o "estojo em forma de flauta para a lança» cujos paralelos são inexistentes.

\section{Espadas}

As tipologias para espadas da idade do Bronze grega são essencialmente tipologias criadas por Sandars ${ }^{(32)}$. Estas baseiam-se na forma de todo o punho, pois este apresenta mais estabilidade e uniformidade de características do que a lâmina ${ }^{(33)}$. Retrataremos não só os exemplares mais tardios mas também analisar alguns iniciais, pois o autor enfatiza bastante o processo evolutivo que as espadas sofrem.

Em cerca do século XV a. C. vimos aparecer na Grécia dois tipos de espadas, as tipo A e B. As espadas tipo A são espadas bastante compridas, chegando a ter cerca de um metro de comprimento, o que faz com que se quebrem facilmente. As suas espigas podem ser estreitas e curtas, unflanged apenas com um buraco de rebite, ou mais longas com dois a três buracos. É caracterizada por ter as espigas e o ombro unflanged. Estas espadas tendem a ficar mais estreitas e leves conforme evoluem. A sua origem é vista como cretense, mas derivada de protótipos do próximo Oriente e aparece em Creta, no Peloponeso, nas Ciclades e nas Ilhas Jónicas.

As espadas do tipo B têm como inovação o uso de flanges no ombro e na espiga. São também espadas mais curtas e mais robustas, logo menos quebráveis. As espigas são largas, compridas e agora flanged, com diversos buracos de rebite. Tem a sua origem atestada na Grécia continental e também parece basear-se em espadas de tradição 
oriental. Aparece essencialmente na Argólida, particularmente em Micenas. Posteriormente, por volta da segunda metade do século XV a. C. surgem as espadas tipo C (chifruda - horned) e as tipo D (cruciforme - cruciform).

As espadas tipo $C$ são uma mistura das tipo $A$ e $B$, possuindo uma lâmina mais estreita que a $A$ e um midrib mais alto e fino. Possui as espigas semelhantes às espadas tipo $\mathrm{B}$, com flanges. $\mathrm{O}$ seu nome deve-se ao guarda-mão ter uma forma chifruda, que é construída no mesmo molde que a lâmina e a espiga e não como uma peça separada. A sua área de dispersão vai desde o Egeu à Palestina, passando pela Bulgária e ex-Jugoslávia.

A espada tipo $\mathrm{C}$ pode dividir-se em tipo $\mathrm{Ci}$ e Cii. A primeira tem sempre dois buracos de rebite na lâmina, perto do ombro, e de um a três no punho. Possui uma extensão estreita e unflanged no fim do pomo, sendo este uma unidade separada. É uma espada comprida na qual os rebites podem ser cobertos com ouro. Este tipo de espada aparece em Cnossos.

O subtipo Cii tem um comprimento médio, o midrib não é tão pronunciado como os anteriores, o punho não tem rebites, e usualmente também não apresenta a extensão da espiga para segurar o pomo. Os chifres característicos nestes exemplares são formados por uma dobra do metal, que aparenta ser martelado. Este tipo aparece em Cnossos e Creta. As espadas tipo D - cruciformes - são também passíveis de ser subdivididas em Di e Dii. A primeira tem um comprimento médio, com excepção de um exemplar de Dendra que é mais comprido. A espiga tem a extensão para o pomo. Este e o punho são flanged, e o guarda-mão possui as pontas de forma larga angular ou arredondada, que the confere o nome cruciforme.

As Dii perdem o midrib e a extensão do pomo torna-se flanged em forma de T. O punho e o pomo são assim construídos sobre esta espiga, normalmente em marfim, osso ou madeira com uma peça única para cada face. Aqui os guarda-mão são sempre arredondados. São espadas algo curtas com punhos fortes. Estão atestados exemplares do início do século XIV a. C. até cerca do LH IIIB.

As espadas tipo F são características do século XIII, com lâminas lisas e ombros quadrados. As flanges tornam-se mais profundas e o pomo em $T$ torna-se mais estreito. Por fim temos as espadas tipo G que são características do século XII a. C. As lâminas continuam estreitas e os pomos em T, mas o ombro ganha a forma de chifres virados para a lâmina - quillons. 
Na passagem do século XIII a. C. para o século XII a. C. denota-se uma quebra na estandardização das espadas do Egeu, havendo variantes locais, até ao aparecimento da espada tipo Naue II.

A maior parte destas espadas pode ser decorada. Os punhos são os mais ornamentados, mas os midribs também o podem ser. No caso de uma espada tipo $\mathrm{C}$ temos o punho decorado com ouro $\mathrm{e}$ desenhos de espirais e penas em repoussé( ${ }^{(34)}$.

Em relação às espadas tipo $A$ e $B$ temos evidências de lâminas com decoração incisa, normalmente com motivos abstractos, punhos com folha de ouro e pomos que são peças talhadas de marfim, alabastro ou mármore. Os rebites em ouro são comuns em época micénica, os rebites em prata aparecem a partir do LH I e II.

Posteriormente aparece a espada tipo Naue II também apelidada de Griffzungenschwert, classificada pela primeira vez por Julius Naue em 1903 na sua obra Die vorromischen Schwerter aus Kupfer, Bronze und Eise ${ }^{(35)}$.

É uma espada característica do final da idade do Bronze e da Idade do Ferro, aparecendo no LH IIIB e, posteriormente, dispersando-se pelo Egeu, Próximo Oriente e Europa tornando-se a espada standard europeia e oriental até ao século VII a. C. ${ }^{(36)}$

A sua inovação consiste em ser forjada de uma única peça de bronze, e mais tarde de ferro. Esta peça única incluía flanges nas pontas da espiga de modo a podem inserir grips de madeira ou osso $^{(37)}$. Para além disto, era uma espada longa, com uma lâmina tipo leaf-shaped, com a espiga plana e possuindo dois midrib(38). A sua grande dispersão está ligada à sua eficácia superior, o que levou a que fosse bastante copiada, havendo assim muitas imitações locais.

As espadas homéricas são "afiadas", "possante", "semelhante a um relâmpago", "temível» e "de bom punho", no que toca a referências genéricas. Em relação à constituição das espadas temos espadas "toda de bronze", "dourada", "de prata", "prateada", "incrustada de prata", "cravejada de prata", "de bronze com adereços prateados", "cravejada de adereços dourados" e "de ouro". As referências a espadas de prata são dos heróis como Agámemnon, Heitor e mesmo Aquiles, e na Odisseia a espada de Ulisses é de prata. A "espada de ouro" é um dos epítetos de Apolo, como tal pode ser apenas uma referência sobrevalorizada ou uma realidade votiva.

Os adereços e incrustações metálicas podem referir-se aos rebites das espadas ou a decorações na zona do punho. A única menção de pormenores dos punhos é uma referência a um "punho de prata" 
da espada de Aquiles na llíada. No que toca a diferenciar tipologias temos a evidência de uma espada "longa" e "comprida" que permite que restrinjamos esta espada aos tipos A e Naue II. No entanto, uma espada de tamanho médio $D$ ou $F$ pode, para Homero ser considerada longa, tornando este tipo de atributo bastante relativo. A referência à "grande espada trácia" mostra as trocas comerciais ou a introdução de populações trácias na Grécia ou na Anatólia. Por fim as diversas menções a espadas "de dois gumes" mostra que não se tratam de espadas com falso gume. Independentemente, não é possível restringi-las a uma tipologia específica.

\section{Comparação das obras}

O principal objectivo é a análise das diferenças cronológicas entre as realidades descritas, de modo a tentar propor datas para as mesmas, definindo assim uma baliza cronológica específica para as obras. Uma vez que ambas as obras possuem bastantes epítetos idênticos, e estes são, salvo em raras excepções, os mais utilizados, iremos apenas mencionar as diferenças entre as obras.

$\mathrm{Na}$ análise comparativa do armamento em geral, as descrições mais ricas pertencem, como seria de esperar, à llíada, ainda assim parece haver poucas diferenças a relatar. Entre elas, no caso dos arcos parece apenas curioso referir que o arco de Ulisses é referido na Odisseia como poderoso e famoso, epítetos nunca utilizados na llíada. Esta obra refere também um arco desnudo, o que se pode referir a uma qualquer falta de revestimento. Este revestimento não aparece atestado em nenhuma das obras, mas que pode referir-se à utilização de pedaços de osso para cobrir certos arcos. No entanto, segundo a llíada, a utilização de chifre parece ser feita com o chifre inteiro, e adornando as pontas com ouro. Podemos ter assim dois tipos diferentes de arco descritos.

Para as aljavas mencionamos a referência da llíada a uma aljava duplamente coberta, mas sem qualquer tipo de interpretação mais concreta. As setas não aparentam qualquer tipo de diferença, com excepção da já comentada seta dourada que não aparece na Odisseia. No que toca às lanças a única excepção parece ser o anel de ouro mencionado na llíada, no entanto, este em si já se pode tratar de uma excepção dado o material em que é feito.

Ainda que as diferenças entre as couraças não sejam dignas de menção, a não referência a armaduras na Odisseia pode indicar uma 
evolução ou inovação que digne a diferente designação. Esta possível diferenciação cronológica pode não passar de, ao retratar uma realidade não bélica, não ser necessária a menção a tal objecto.

$\mathrm{Na}$ comparação, parece significativa a menção unicamente a metais para as cnémides da llíada enquanto a Odisseia apenas menciona o cabedal. Esta diferenciação poderia mostrar uma evolução, pois aparentemente estas foram inicialmente manufacturadas em materiais perecíveis e só posteriormente em metal. Mas dado que tal dedução se baseia numa única referencia na Odisseia podemos estar a tirar conclusões precipitadas.

Apesar das descrições de escudos na Odisseia serão escassas e nunca poderem sequer comparar-se à descrição de um escudo heróico, elas mencionam as principais características dos escudos - decoração, construção em camadas, e uso da pele para o fabrico. No entanto, não existe uma única menção ao metal, com excepção do escudo «manchado pela humidade» que tanto pode ser de cabedal como de metal.

Ainda que algumas tipologias referentes aos escudos dos heróis já tenham sido analisadas, a introdução dos mesmos num contexto temporal específico torna-se deveras difícil. Podemos pensar que a não referência ao metal na Odisseia faz com que esta pertença a uma fase mais antiga, mas não podemos certamente referir que fase. Para a llíada o Bronze Final parece claramente atestado, uma vez que o ferro não é uma parte integrante desta arma, não podendo inseri-la num contexto de Idade do Ferro plena. Mas o período do Bronze Final e início do Ferro é ainda bastante extenso e com bastantes diferenças entre si.

A comparação das realidades relativas ao elmo tem o mesmo problema que as outras realidades militares - poucas evidências na Odisseia - mas ainda assim não se denota nenhuma grande modificação. A decoração é intensivamente demonstrada na llíada, enquanto na Odisseia a única menção que pode levar a pensar em decoração é a descrição de um elmo como sendo "lindíssimo". Por outro lado a Odisseia menciona as protecções faciais enquanto a llíada não faz qualquer referência a essa característica. Em qualquer dos casos, não nos parece viável pensar em grande diferenças cronológicas entre as obras.

Para as espadas não temos qualquer diferença a anotar, pois, não sendo possível demonstrar claramente a menção a espadas tipo Naue II, não se torna possível uma distinção entre a Idade do Bronze e a Idade do Ferro. 


\section{Conclusão}

A pouca menção ao ferro é vista como um atributo da Idade do Bronze. No entanto, como a maior parte das mudanças na história, a introdução do ferro foi um processo gradual, o que também permite olhar as obras como representando o início da Idade do Ferro. Do mesmo modo, uma das principais alterações na transição bronze/ferro foi a queda dos palácios. Independente da interpretação, no parecer algo magnânimo de Drews (1995) sobre o tema, a realidade é que os palácios cessam o seu funcionamento no fim do Bronze. Como tal, a constante menção aos mesmos ao longo das obras é mais uma evidência da datação micénica dos acontecimentos.

Em relação aos materiais temos diversos autores que se apoiam no que julgam ser referências a fíbulas para defender uma sociedade da Idade do Ferro. No entanto, tal como a espada Naue II é uma realidade anterior ao início da Idade do Ferro, a fíbula também tem os seus primeiros vestígios na Grécia antes de acabar a Idade do Bronze.

Após a longa análise material, contraposta com as evidências históricas, e esta breve análise a certos pormenores, conseguimos perceber a polémica que a obra levanta. Homero decide confundir-nos, atirando-nos pedaços de evidências como que para alimentar um animal faminto, mas o animal é sedento de curiosidade e os estudos das obras não cessarão. Procurámos chegar mais longe percorrendo o caminho ditado pelo autor, mas o espaço é curto e as evidências demasiadas, podendo apenas concluir que os palácios e o fausto de uma época áurea têm forte concorrência com o ferro e o equipamento militar evoluído.

Mas não é só a cronologia geral que nos deixa num impasse cronológico de difícil resolução. A comparação das duas obras também nos faz oscilar, analisando ora uma evidência mais recente na llíada ora outra na Odisseia. Parece-nos assim, que não é possível analisar as evidências como se de provas matemáticas se tratassem, uma vez que nenhuma predomina sobre a outra.

As constantes provas de sociedades mais evoluídas passíveis de ter existido aquando da queda de Tróia adicionadas às evidências do inicio da Idade do Bronze, levam-nos a pensar as realidades descritas como uma amálgama de conhecimentos por vezes concretos e objectivos, por vezes difusos, de toda uma realidade extensível por diversos séculos, que é compilada ao sabor da necessidade e da criatividade do autor em obras complementares mas distintas. Compreende-se 
assim, talvez não tanto uma realidade objectiva das sociedades descritas, mas o modo de expressão e produção literária de um autor grego do século XVIII perante as fontes históricas que lhe eram acessíveis.

\section{Notas}

(1) C. W. BLEGEN, Troy and the Trojans, London, Thames and Hudson, 1963, 168-169.

(2) Ibid., 174

(3) M. H. da ROCHA PEREIRA, Estudos de Historia da Cultura Clássica I - Cultura Grega, Lisboa, Fundação Calouste Gulbenkian, 2006, 56-61.

(4) Apud M. H. da ROCHA PEREIRA, Estudos de Historia da Cultura Clássica I - Cultura Grega, Lisboa, Fundação Calouste Gulbenkian, 2006, 51.

(5) M. H. da ROCHA PEREIRA, Estudos de Historia da Cultura Clássica I - Cultura Grega, Lisboa, Fundação Calouste Gulbenkian, 2006, 54.

(6) R. DREWS, The End of the Bonze Age - changes in warfare and the catastrophe ca. 1200 B.C., Princeton, University Press, 1995.

(7) A. J. B. WACE, E. H. STUBBINGS, A Companion to Homer, London, Macmillan, 1970.

(8) Ibid.

(9) C. W. BLEGEN, Troy and the Trojans, London, Thames and Hudson, 1963, 145-146.

(10) Apud C. W. BLEGEN, Troy and the Trojans, London, Thames and Hudson, 1963, 156.

(11) A. J. B. WACE, E. H. STUBBINGS, A Companion to Homer, London, Macmillan, 1970, 513-514.

(12) A. J. B. WACE, E. H. STUBBINGS, A Companion to Homer, London, Macmillan, 1970, 510.

(13) Ibid.

(14) Apud A. J. B. WACE, E. H. STUBBIngS, A Companion to Homer, London, Macmillan, $1970,512$.

(15) A. J. B. WACE, E. H. STUBBINGS, A Companion to Homer, London, Macmillan, 1970, 512.

(16) R. DREWS, The End of the Bonze Age - changes in warfare and the catastrophe ca. 1200 B. C., Princeton, University Press, 1995, 178.

(17) Com excepção do escudo de Aquiles.

(18) A. J. B. WACE, E. H. STUBBINGS, A Companion to Homer, London, Macmillan, 1970, 513.

(19) Ibid. pp. 506-507.

(20) Ibid. pp. 507-509.

(21) Ibid. pp. 508-509.

(22) Ibid. p. 509.

(23) Ibid. p. 508. 
(24) R. DREWS, The End of the Bonze Age - changes in warfare and the catastrophe ca. 1200 B.C., Princeton, University Press, 1995, 111.

(25) A. J. B. WACE, E. H. STUBBINGS, A Companion to Homer, London, Macmillan, 1970, 508.

(26) R. DREWS, The End of the Bonze Age - changes in warfare and the catastrophe ca. 1200 B.C., Princeton, University Press, 1995, 176-177.

(27) D. FORTENBERRY, "Single Greaves in the Late Helladic Period", AJA 95/4, 1991, 623-627.

(28) Ibid.

(29) R. DREWS, The End of the Bonze Age - changes in warfare and the catastrophe ca. 1200 B.C., Princeton, University Press, 1995, 124.

(30) A. J. B. WACE, E. H. STUBBINGS, A Companion to Homer, London, Macmillan, 1970.

(31) Ibid.

(32) N. K. SANDARS, "The First Aegean Swords and Their Ancestry", AJA 65/1, 1961 e

N. K. SANDARS, "Later Aegean Bronze Swords", AJA 67/2, 1963

(33) N. K. SANDARS, "Later Aegean Bronze Swords", AJA 67/2, 1963, 117-153.

(34) Ibid.

(35) AA.VV., "The Naue Type Sword ca. 1200 - 700 b. C.», 2006 [Consult. Julho 2008]. Disponivel em WWW: <URL:http://www.eclectichistorian.net/Griffzungenschwert/>.

(36) R. DREWS, The End of the Bonze Age - changes in warfare and the catastrophe ca. 1200 B.C., Princeton, University Press, 1995, 194.

(37) AA.VV., "The Naue Type Sword ca. 1200 - 700 b.C.", 2006 [Consult. Julho 2008]. Disponivel em WWW: <URL:http://www.eclectichistorian.net/Griffzungenschwert/>.

(38) R. DREWS, The End of the Bonze Age - changes in warfare and the catastrophe ca. 1200 B.C., Princeton, University Press, 1995, 193-194. 